See Article page 691.

\section{Commentary: Guideline-directed therapy is extremely valuable, but not always current or followed}

\author{
Andrea J. Carpenter, MD, PhD, and Dawn Hui, MD
}

In this issue of the Journal, Lazar ${ }^{1}$ has written a thoughtful review of guideline directed therapy for patients after coronary artery bypass grafting. His summary is based strongly on the American Heart Association Scientific Statement published in $2015 .^{2}$ This article makes clear that surgeon performance regarding guideline-directed therapy is highly variable and generally poor. As surgeons, we must be aware of guidelines and apply them effectively for each patient, but we must also be cognizant of current literature and individual patient needs.

For example, excellent literature has supported changes in the management of blood pressure (BP). ${ }^{3-5}$ As characterized in a summary of the 2017 multisociety guidelines, "the benefit of pharmacologic treatment for $\mathrm{BP}$ reduction is related to atherosclerotic CVD (ASCVD) risk," and use of such medications is recommended for secondary prevention of recurrent events. ${ }^{6}$ The Systolic Blood Pressure Intervention Trial (SPRINT) results demonstrated that more intensive systolic BP control, with a goal of systolic BP lower than $120 \mathrm{~mm} \mathrm{Hg}$ rather than lower than $140 \mathrm{~mm} \mathrm{Hg}$, was associated with fewer major cardiovascular events. This trial excluded patients with diabetes, however, and noted a higher adverse event rate with the lower BP. Subsequently, a network analysis of 17 randomized trials concluded that a target systolic BP lower than $130 \mathrm{~mm} \mathrm{Hg}$ achieved optimal balance between efficacy and safety. ${ }^{4}$ In addition, the original guidelines addressed angiotensin-converting enzyme inhibitors as optimal first line therapy for hypertension; however, $10 \%$ of patient will be intolerant of angiotensin-

\footnotetext{
From the Department of Cardiothoracic Surgery, Joe R. and Teresa Lozano Long School of Medicine, University of Texas Health San Antonio, San Antonio, Tex. Disclosures: Authors have nothing to disclose with regard to commercial support. Received for publication Nov 18, 2019; accepted for publication Nov 18, 2019; available ahead of print Dec 9, 2019.

Address for reprints: Andrea J. Carpenter, MD, PhD, Department of Cardiothoracic Surgery, Long School of Medicine, UT Health San Antonio, 7703 Floyd Curl Dr, MC 7841, San Antonio TX, 78229 (E-mail: Carpentera2@uthscsa.edu).

J Thorac Cardiovasc Surg 2020;160:699-700 $0022-5223 / \$ 36.00$

Copyright $(2020$ Published by Elsevier Inc. on behalf of The American Association for Thoracic Surgery

https://doi.org/10.1016/j.jtcvs.2019.11.089
}

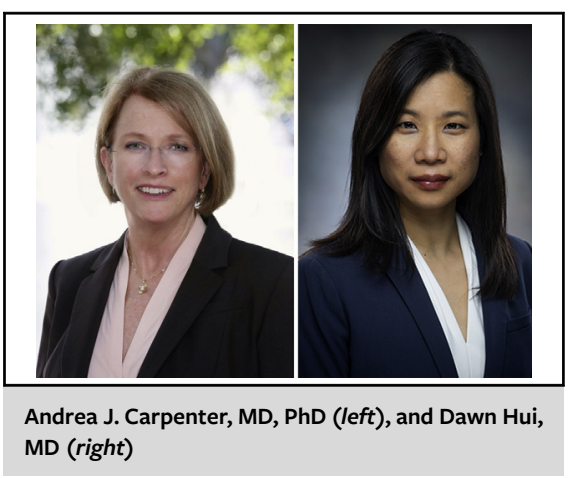

CENTRAL MESSAGE

Surgeons must actively consider and initiate perioperative guideline-directed therapy to support optimal long-term outcomes for patients undergoing surgical revascularization.

converting enzyme inhibitors, and treatment with angiotensin receptor blocking medications are a perfectly acceptable alternative.

We must also consider patient access to medication. The best drug available is of no use on the pharmacy shelf. Giving a prescription is not the same as ensuring that the patient receives treatment. We should be sensitive to cost and insurance formulary benefits to be confident the patient can follow medical therapy. Our postoperative visit is the optimal time to check whether the patient has received the medications and complied with therapy. Polypharmacy may also be a barrier to patient compliance, and counseling on simple nonpharmacologic changes, such as sodium intake, ${ }^{7}$ alcohol consumption, ${ }^{8}$ and weight reduction, may modulate pharmacologic needs and thus improve adherence.

As surgeons we should have a strong interest in this topic. We are generally familiar with literature that supports complete revascularization and longer-term efficacy of coronary artery bypass grafting relative to percutaneous coronary intervention or medical therapy. We should not surrender that benefit by failing to do all that we can to optimize long-term care that has demonstrated benefit. We should also be aware of current information that may improve on previously published guidelines. We obviously do not, and cannot, follow our postoperative patients lifelong. We 
really must start them on the optimal path, however, when we send them back to their referring physicians.

\section{References}

1. Lazar HA. The surgeon's role in optimizing medical therapy and maintaining compliance with secondary prevention guidelines in patients undergoing coronary artery bypass grafting. J Thorac Cardiovasc Surg. 2020;160:691-8.

2. Kulik A, Ruel M, Jneid H, Ferguson TB, Hiratzka LF, Ikonomidis JS, et al; American Heart Association Council on Cardiovascular Surgery and Anesthesia. Secondary prevention after coronary artery bypass graft surgery: a scientific statement from the American Heart Association. Circulation. 2015;131:927-64.

3. Whelton PK, Carey RM, Aronow WS, Casey DE Jr, Collins KJ, Himmelfarb CD, et al. 2017 ACC/AHA/AAPA/ABC/ACPM/AGS/APhA/ASH/ASPC/NMA/ PCNA guideline for the prevention, detection, evaluation, and management of high blood pressure in adults: a report of the American College of Cardiology/
American Heart Association Task Force on Clinical Practice Guidelines. J Am Coll Cardiol. 2018;71:e127-248. Erratum in: J Am Coll Cardiol. 2018;71:2275-9.

4. Bangalore S, Toklu B, Gianos E, Schwartzbard A, Weintraub H, Ogedegbe G, et al. Optimal systolic blood pressure target after SPRINT: insights from a network meta-analysis of randomized trials. Am J Med. 2017;30:707-19.e8.

5. SPRINT Research Group, Wright JT Jr, Williamson JD, Whelton PK, Snyder JK, Sink KM, et al. A randomized trial of intensive versus standard blood-pressure control. N Engl J Med. 2015;373:2103-16.

6. Rubenfire M. 2017 Guideline for High Blood Pressure in Adults. Available at: https://www.acc.org/latest-in-cardiology/ten-points-to-remember/2017/11/09/11/ 41/2017-guideline-for-high-blood-pressure-in-adults. Accessed October 10, 2019.

7. Strazzullo P, D'Elia L, Kandala NB, Cappuccio FP. Salt intake, stroke, and cardiovascular disease: meta-analysis of prospective studies BMJ 2009;339:b4567.

8. Roerecke M, Kaczorowski J, Tobe SW, Gmel G, Hasan OSM, Rehm J. The effect of a reduction in alcohol consumption on blood pressure: a systematic review and meta-analysis. Lancet Public Health. 2017;2:e108-20. 